\title{
A avaliação como conhecimento utilizável para reformas de gestão pública*
}

\section{Introdução}

As reformas do setor público utilizam a avaliação? Quais as boas práticas que a experiência trouxe à tona? A avaliação tem futuro?

No presente relatório, a avaliação é definida como um meio de aperfeiçoar a capacidade de aprender como conduzir mudanças bem-sucedidas e definir resultados alcançáveis nos campos da eficiência e eficácia públicas. Ainda que existam muitas formas, a avaliação pode ser caracterizada, em linhas gerais, como uma atividade dedicada à produção e análise de informações relevantes e pertinentes a respeito da relação entre os atos públicos, seus resultados e impactos.

\section{Um paradoxo aparente}

É difícil imaginar reformas na gestão administrativa e no setor público desenvolvidas e implementadas aleatoriamente, por ordem de um decreto ou das autoridades hierárquicas. Nesse caso, existe uma demanda ampla por parte de seus executores, pois existem deficiências significativas no monitoramento das mudanças introduzidas no setor público. Há motivos para crer que a avaliação está destinada a desempenhar um papel importante no atendimento dessas expectativas, pelo menos em parte, uma vez que ela fornece ferramentas relativamente rigorosas e uma abordagem amplamente racional — teoricamente — para a produção de informações e recomendações sobre política pública específica.

Contudo, um exame cuidadoso dos fatos demonstra que, na maior parte dos países, a avaliação, até o momento, foi utilizada de maneira

\footnotetext{
Jean-Claude

Thoenig é diretor de

Pesquisa

do Centro

Nacional

de Pesquisa

Científica,

do Grupo de

Análise de

Políticas

Públicas e

professor

no Institution

Européenne

d'Administration

des Affaires

INSEAD

Traduzido por

René Loncan
} 
limitada e esporádica, e que muitas vezes mostrou ser ineficaz. Existem razões para crer que a relutância em usar a avaliação amplamente não se deve necessariamente à ignorância ou à má-vontade. Como resultado, muitas vezes, os governos afirmam publicamente a necessidade de avaliação, porém falham em praticar o que pregam. Um exemplo dessa tendência é fornecido pelo White Paper sobre políticas administrativas e de pessoal, publicado na Noruega, o qual ressalta a importância de avaliar os problemas e reformas específicas dessas áreas. Porém, nenhuma iniciativa foi lançada subseqüentemente para avaliar os dez anos de reformas realizadas, pelo contrário, pode-se encontrar um relativo ceticismo para com a avaliação, particularmente, entre praticantes bem-informados e experientes em reforma da gestão pública, alguns até mesmo expressam uma resistência à avaliação que parece predominar no seu próprio governo. Tal atitude pode advir de várias causas: a relutância dos formuladores de políticas de se sentirem desafiados pelos especialistas, os quais não participam efetivamente do processo; a arrogância dos avaliadores em definir as metas e o conteúdo das reformas; o fato de que as avaliações exigem muito tempo para serem feitas; a idéia de que reformas também são uma ferramenta política do governo etc. As exigências por parte dos formuladores de políticas parecem permanecer. A experiência sugere que a avaliação pode ser um problema quando os ministros temem que eles sejam constrangidos pelas informações geradas pelos avaliadores, desejando ouvir apenas as boas notícias e não o que deu errado; ou que o público e a imprensa podem usá-las como uma oportunidade para criticar os governos (Kessler, Lascoumes, Setbon, Thoenig, 1998). Esse paradoxo, porém, é mais aparente do que real, e seria um erro desprezar todo o processo em virtude de sua execução.

Admitimos, de um ponto de vista quantitativo, de que não há motivos para concluir que exista uma tendência irresistível ao uso generalizado da avaliação. Nesse sentido, num grande número de países, a reforma da gestão pública parece estar se arrastando ou estar relativamente defasada em relação a outras áreas de políticas governamentais relevantes: pesquisa e desenvolvimento, saúde, previdência, educação ou assistência social. Em contrapartida, a prática mostrou que a avaliação acontece e é utilizada para fornecer informações aos governos.

Sem tentar elaborar uma lista extensa, podemos rever um certo número de exemplos recentes de reformas de gestão pública que foram acopladas a trabalhos ou práticas de avaliação genuínas.

Em 1995, o governo finlandês lançou um programa articulado e detalhado, visando identificar e avaliar os resultados produzidos por uma série de reformas importantes, implementadas desde meados dos anos 80. Esse programa incluiu grupos de funcionários públicos com vasta experiência, 
envolvidos nas reformas, e equipes de especialistas, incluindo os especialistas estrangeiros (Pollitt et al, 1997).

A França acoplou suas políticas de modernização administrativa a uma série de avaliações contínuas já no final dos anos 80 . Os ministérios, tais como o Ministère de l'Equipement, realizaram um esforço de avaliação intenso e participativo, particularmente com relação à gestão dos objetivos e recursos alocados aos seus serviços externos (Trosa, 1992).

Em 1995, na Nova Zelândia, a Comissão de Serviços Estatais e o Tesouro incumbiram um acadêmico norte-americano de realizar uma avaliação — independente — das mudanças produzidas por uma ampla reorganização do setor público em termos estruturais, organizacionais, estratégicos, financeiros e orçamentários, e de controle de gestão (Schick, 1996). Mais recentemente, esse mesmo país produziu um relatório chamado Estado do Estado. Por fim, uma agência central recebeu a responsabilidade de realizar uma coleta sistemática de dados sobre o desempenho geral do sistema público e do desempenho individual de cada uma de suas agências.

As iniciativas que sinalizam as futuras reformas na gestão pública são abordagens interessantes e são adotadas em vários países. Esse é o caso do Canadá, onde uma abordagem estruturada e duradoura está sendo realizada. Publica-se um relatório anual que estabelece quais são as questões consideradas administrativas centrais e as prioridades a serem atendidas no próximo ano. O Escrivão do Gabinete do Conselho Privado, ligado ao Primeiro Ministro, publica um documento que oferece orientação estratégica para a reforma da gestão. Em conjunto com todos os vice-ministros, ele estabelece forças-tarefa, monitora a revisão do programa da reforma e investiga estes assuntos: fornecimento de serviços a cidadãos e gestão de assuntos inter-setoriais ou interagênciais. A idéia é promover a coordenação horizontal, com o objetivo de melhorar a consistência das iniciativas, e seu impacto sobre a implementação de programas, nos vários campos da responsabilidade governamental. Essa abordagem de cima para baixo é suplementada por uma de baixo para cima, uma vez que cada departamento é encorajado a coletar suas próprias informações sobre os resultados e progressos obtidos no seu próprio setor. Isso visa adaptar a avaliação aos vários níveis dentro do sistema público, cobrindo simultaneamente duas facetas, a da eficiência interna e a da eficácia externa, e incluindo tanto estruturas quanto processos.

Uma imagem mais completa poderia ser fornecida se essas situações não estivessem limitadas a iniciativas formais ou tradicionais de avaliação, uma vez que alguns países têm práticas que poderiam ser descritas como quase-avaliações. Sem ter status formal ou serem conduzidas como projetos específicos sistematicamente elaborados, existem iniciativas, por meio das quais, os formuladores de políticas e suas equipes coletam informações e 
conduzem revisões e avaliações de vários aspectos de suas reformas, tanto antes como depois de tomarem decisões. Essa abordagem quase informal e ad hoc é encontrada em diversos graus e em vários países.

No Reino Unido foram realizadas revisões de várias reformas, abordando aspectos específicos de cada programa, como Next Steps (Próximos Passos), Citizen's Charter (Carta do Cidadão) ou Market Testing and Contracting Out (Teste de Mercado e Terceirização). Na Irlanda, a Comissão para Pesquisa da Gestão Pública, que é dirigida pelo Departamento de Finanças, acaba de efetuar uma revisão parcial dos planos da seção de atendimento ao usuário nos departamentos e escritórios, por meio de um trabalho escrito. No final, mesmo que os resultados sejam limitados, eles estão longe de serem neglicenciáveis.

Duas observações gerais poderiam ser feitas nesse estágio. A primeira é que a avaliação, não é, por natureza, característica de um tipo específico de Estado ou cultura administrativa, mesmo que os exemplos dados acima sugiram que ela seja mais utilizada em países onde as reformas são mais amplas, ou as atitudes anglo-saxônicas predominam. A segunda sugere que não é suficiente ter especialistas internos ou externos qualificados, ferramentas confiáveis e informações amplas para uma consciência da importância da avaliação espalhar-se automaticamente através do sistema e ser incorporada na gestão das reformas. A avaliação pode ser praticada até mesmo se o sistema público não é permeado por uma cultura de avaliação. A lição a ser aprendida é relativamente otimista: não são especialistas ou sistemas sofisticados que contam, uma vez que servidores públicos individuais são livres para decidir se eles irão realizar uma avaliação ou não, muitas vezes sem perceberem conscientemente o que estão fazendo. Em outras palavras, as barreiras para a avaliação não são tanto profissionais, técnicas ou intelectuais, mas sim, pragmáticas.

\section{Aprendendo com as boas práticas}

Sob que condições as práticas de avaliação podem ser utilizadas para desenvolver e implementar reformas no setor público? A resposta é óbvia: quando elas são adotadas e utilizadas pelos formuladores de políticas. Entretanto isso não pode ser feito aplicando-se uma fórmula pronta ou seguindo-se um único modelo de procedimento das melhores práticas. O exame de boas práticas pode ensinar algumas lições.

A observação das práticas de avaliação torna possível refutar clichês ou estereótipos que encorajam o ceticismo ou fatalismo a respeito da possibilidade da avaliação bem-sucedida. Por exemplo, ouve-se com frequiência que, por natureza, as organizações públicas não são auto-avaliadoras (Wildavsky, 1979). Em outro nível, o problema é colocado nas mãos dos 
formuladores de políticas, cuja forma de pensar é apresentada como sendo incompatível com o interesse na prática da avaliação, com raras exceções. Existem outros argumentos supostamente corretos no sentido de que o problema reside na própria natureza das reformas realizadas. Por exemplo, argumenta-se que políticas abrangentes, autoritárias, como aquelas que transferem setores completos de bens e serviços ao mercado, visto que eles são ideologicamente motivados, não encorajam o governo a focalizar custos e benefícios esperados e gerados. Porém, concluir que, por essa razão, nada possa ser esperado da avaliação, parece ser tão extremo como afirmar que ela é a inevitável onda do futuro.

\section{Utilidade para a ação}

A primeira lição é que uma abordagem pragmática é necessária para o uso das práticas de avaliação. Em outras palavras, estas precisam, em cada caso, enfocar necessidades e oportunidades específicas para a ação.

As necessidades dos formuladores de políticas deveriam ser mantidas em evidência ao decidir o que avaliar. Essa observação de senso comum não é abstrata nas suas implicações. A decisão de avaliar um programa raramente é feita unilateralmente apenas pelos tomadores de decisão. O trabalho de um grupo de especialistas da Organização para Cooperação e Desenvolvimento Econômico (OCDE) sugere duas observações. As necessidades, muitas vezes, não são formuladas claramente de antemão pelos formuladores de políticas e, quando o são, os funcionários mais antigos, envolvidos na reforma, desempenham um papel importante em tomar a iniciativa para utilizar práticas de avaliação (o papel que o departamento de orçamento ou o ministério pode desempenhar nesse sentido também deveria ser mencionado). Em alguns países a disposição de funcionários e conselheiros mais antigos para o uso de práticas de avaliação não é coincidência, estando intimamente ligada ao fato de que seu treinamento universitário e profissional os tornou conscientes das contribuições das ciências sociais e da gestão moderna, ao contrário de funcionários com treinamento estritamente jurídico ou administrativo.

São mínimas as possibilidades de que a avaliação seja adotada por si mesma, pois ela não é um fim, mas um meio para um fim. Ela somente será crível e aceitável se atender a três condições: ser patrocinada por indivíduos e grupos que são reconhecidos como tendo experiência prática com avaliação, bem como acesso direto aos formuladores de políticas, ou até mesmo um papel de elaboração de políticas na reforma (tanto antes como depois da sua implementação); estar baseada em uma necessidade ou problema concreto enfrentado pelos formuladores de políticas e do qual eles obterão valor adicionado ao seu nível; e acontecer em tempo oportuno com relação à reforma. 
Essas oportunidades muitas vezes demonstram ser cruciais, especialmente quando a prática da avaliação ainda é incomum dentro de um país ou nos sistemas públicos em que ela já é mais difundida. Timing inadequado pode matar uma iniciativa de reforma. Se a avaliação está em descompasso com a agenda governamental, conseqüentemente não terá nenhum impacto e será simplesmente arquivada e esquecida (isso foi o que aconteceu na França entre 1992 e 1997). Da mesma forma, isso também significa que os sistemas de avaliação precisam ser flexíveis e adaptáveis às instabilidades da ação pública, e que os formuladores de políticas precisam ter acesso fácil ou controle total dessas atividades.

\section{A prioridade: fornecer informação}

O segundo exemplo de boas práticas refere-se ao foco e ao conteúdo das próprias práticas de avaliação. Se o uso da avaliação é orientado para a ação, isso significa que a avaliação se concentra em fornecer conhecimento utilizável. Mais concretamente: é muito mais provável que a avaliação seja aceita e útil se o aspecto de fornecer informação for ressaltado; ao mesmo tempo que se deve usar cautela ao se chegar a uma avaliação ou julgamento. Nesse sentido, a diferença entre avaliação e quase-avaliação, mesmo que seja uma diferenciação teórica que satisfaça puristas metodológicos, é artificial e prejudicial.

Uma avaliação utilizável é, em primeiro lugar e acima de tudo, aquela que visa tornar disponível informações baseadas em dados empíricos, tal como o exame das experiências práticas na reforma do serviço público tem mostrado repetidamente. O motivo para isso está claro e reside na própria natureza do processo de tomada de decisão. Mais especificamente, dois fatos significativos podem ser destacados.

Os dirigentes do setor público são bastante parecidos com os executivos das grandes empresas privadas (Minstzberg, 1980). Eles dão prioridade a informações práticas ou qualitativas, obtidas por meio de conversas com indivíduos em quem confiam. Isso está muito longe do modelo teórico que supõe que aqueles que encontram melhores soluções levam tempo para repensar o problema analisando e revisando exaustivamente todas as informações sobre a situação empírica específica e os méritos quantitativos das alternativas disponíveis. Isso significa que a avaliação é muito mais crível se ela estiver adaptada à realidade do processo de tomada de decisão.

Seja como for, formuladores de políticas engajados na ação não param de pensar. A análise, ou avaliação, é um dentre vários inputs que eles utilizam normalmente: conhecimento, aprendizagem, solução interativa de problemas etc. Conseqüentemente, a análise precisa competir com esses inputs (Lindblom e Cohen, 1979) e não recebe prioridade automaticamente. 
Esses dois fatos apontam para um conceito de avaliação como uma atividade que é relativamente limitada no seu alcance, focaliza problemas claramente definidos, emprega uma linguagem que os formuladores de políticas conseguem compreender, utiliza dados disponíveis mesmo que eles não sejam perfeitos e descreve um estado de coisas mais do que o analisa. Avaliadores sabem como ser sensíveis às condições que são diferentes em cada caso e como utilizar dados, não necessariamente como um argumento competitivo, mas como um meio de obter a atenção dos formuladores de políticas, fornecendo informações ao invés de explicações, e assistência ao invés de julgamento.

Essa tentativa de dar à avaliação maior credibilidade supõe que os avaliadores não emitem julgamentos precipitadamente. Isso é especialmente verdadeiro quando eles precisam avaliar reformas em andamento, uma vez que correm o risco não apenas de substituir seu próprio julgamento pelo dos formuladores de políticas - desvio tecnocrático - mas de não conseguir fornecer um parecer objetivo da situação, particularmente ao enfocar erros, disfunções ou deficiências, sem equilibrá-las adequadamente com as realizações, progressos e êxitos, o que leva a um preconceito pessimista.

Essa falta de visão seletiva de uma avaliação em andamento, quanto ao verdadeiro impacto de uma política, é encontrada em um grande número de iniciativas de reforma. Por exemplo, o governo canadense é especialmente cuidadoso em relação a relatórios de auditores que tendem a enfatizar as falhas de uma reforma (tanto em termos de custo-benefício como de eficácia externa) e dão a impressão de que pouco progresso está sendo feito, mas que ainda há muito por se fazer. Nesse caso a avaliação não representa nenhuma ajuda prática para os governos e, devido a sua função geral de apreciação, seleciona informações que tornam difícil elaborar os próximos passos da reforma, tornando-se assim, de certa forma, contraproducente.

Avaliações deveriam emitir julgamentos? $\mathrm{O}$ debate permanece bastante aberto na comunidade profissional e entre os promotores da reforma. Alguns executores da reforma defendem que as avaliações não deveriam gastar tempo e energia fazendo julgamentos, tornando-se assim exploratórias ou informativas. Entretanto, eles devem estar conscientes de que muitas vezes julgamentos estão envolvidos, mesmo quando não verbalizados. Porém, pontos de vista igualmente fortes esperam que avaliadores emitam julgamentos: não fazê-lo reduziria o valor do aprendizado da avaliação, especialmente quando os ministros desejam obter uma visão clara da situação. Aprender implica em julgar.

\section{Avaliação interna}

O terceiro exemplo de boas práticas é a avaliação interna, que cobre a auto-avaliação, bem como avaliações externas solicitadas a acadêmicos 
ou especialistas privados. Os formuladores de políticas responsáveis por reformas do serviço público serão inclinados a utilizar a avaliação e irão constatar que ela se torna muito mais fácil de realizar quando as práticas de avaliação são desenvolvidas dentro do próprio sistema público, particularmente, nos níveis que iniciam, elaboram e implementam a reforma.

Vários países solicitaram que especialistas privados ou acadêmicos conduzissem a avaliação. Essa avaliação tende a ser menos útil para os governos, pois permanece um tanto quanto teórica na medida em que sua abordagem enfoca aspectos ou temas que não se relacionam com as preocupações específicas dos governos, tais como: a agenda real da reforma, o ritmo da implementação da política e a capacidade dos formuladores de políticas. Uma análise geral pode considerá-la crítica ou passiva, pois tratase de uma avaliação posterior, realizada vários meses ou até mesmo anos após os eventos terem ocorrido e, portanto, fornece poucas orientações e instruções para as próximas etapas na área. As limitações e frustrações são vistas mais claramente quando, como na Finlândia, por exemplo, concomitantemente, são realizadas avaliações internas por grupos ou redes de servidores públicos diretamente envolvidos na implementação das reformas. $\mathrm{O}$ valor adicionado por ação neste caso é comparativamente maior. Deve-se ressaltar que uma avaliação externa pode ser a solução em casos excepcionais, por exemplo, quando um governo considerar politicamente eficaz ter especialistas externos convencendo-o a aceitar um programa de reforma do setor público que ele, então, colocará em prática. Esse foi o caso da reforma na gestão de fundos estruturais da União Européia, adotada na Grécia de 1994 a 1996.

É necessário definir também o que se entende por avalição interna. Alguns países, como a França, os Países Baixos e o Reino Unido possuem entidades administrativas (quadro de auditores, por exemplo) ou instituições ad hoc (grupo de trabalho de reforma administrativa ou unidades encarregadas de avaliar políticas públicas). Porém, a existência dessas entidades de avaliação de políticas públicas não assegura que a avaliação da reforma do setor público seja confiada a essas instituições, ou que seus trabalhos serão relevantes.

A avaliação contribui para confirmar a existência de forças contrárias e autonômas no setor público. Essa estratégia é pouco realista. A avaliação não está nas mãos de quem detém as políticas de reforma de gestão pública, por isso, grupos internos de profissionais fazem muito pouco para tornar a avaliação útil para a elaboração de políticas. Os obstáculos mencionados acima mostram que o avaliador corre o risco de se colocar como juiz que pronuncia um veredicto favorável ou desfavorável, sem ser responsável por ele.

As implicações operacionais dessas observações são bastante claras. As reformas da gestão pública são, em vários aspectos, diferentes de 
outras políticas (que podem se referir a questões sociais mais visíveis ou tangíveis, como saúde, educação etc.) e também são consideradas manifestações altamente simbólicas da ação discricionária do governo. Assim, se a avaliação deve ser útil, os próprios formuladores de políticas precisam levá-la em consideração e ajustá-la de acordo com suas necessidades e vontades. A tendência em direção a avaliações internas reflete a determinação dos responsáveis pela reforma em manter em avaliação contínua os diferentes tipos de organização do setor público. De outra forma a avaliação tornar-se-á um ritual meramente burocrático e os relatórios de especialistas serão simplesmente arquivados.

\section{Uma abordagem incremental e oportuna}

As boas práticas sugerem que a avaliação pública deveria ser cada vez mais adotada.

Como já foi mencionado, qualquer um pode realizar uma avaliação; e uma quase-avaliação pode ser uma maneira adequada de se começar. Não há maneira mais certa de se imobilizar a avaliação na sua concepção do que submetendo-a a princípios metodológicos. Além do mais, a prática não é prerrogativa exclusiva dos altos escalões de formuladores de políticas e de sua equipe mais próxima. Há formas de disseminar a avaliação através das agências e da cadeia de comando, desde que ela esteja relacionada ao problema que é relevante para aqueles que a estão executando. Essa avaliação de base ampla é encontrada nos casos em que a reforma está direcionada para as estruturas e processos internos do sistema público e foi implementada por meio de uma abordagem participativa e descentralizada, ou do monitoramento contínuo do governo de um programa de reforma. Exemplos desse tipo de avaliação podem ser encontrados em um setor ou ministério específico, no Ministère de l'Equipement, na França, por exemplo, ou em todo o sistema público, como no caso do Canadá, para o governo federal como um todo. A abordagem incremental também significa que a informação obtida e seus usos para a reforma, fazem sentido para todos os envolvidos, dos formuladores de políticas até os auxiliares administrativos, e não são percebidos como ameaça ou restrição, mas como um recurso e uma oportunidade.

É necessário relativizar a questão dos procedimentos e dos diferentes tipos de abordagens ou métodos. Boas práticas não revelam que alguns métodos, ou conjunto de abordagens, são intrinsecamente melhores que outros. Contudo, desde que a questão da utilidade para a ação continue sendo o critério básico, ou seja, que as considerações técnicas sejam baseadas em como a avaliação será utilizada, as seguintes observações podem ser feitas:

- do ponto de vista técnico, a avaliação deveria levar em consideração os dados empíricos que estão disponíveis ou que podem ser obtidos 
rapidamente a baixo custo, sabendo que os sistemas públicos têm relativamente poucos dados sobre desempenho e eficácia;

- a avaliação não deveria visar tanto a compreensão geral de uma gama de parâmetros, mas sim, produzir indicadores sobre poucos aspectos bem definidos que podem ser considerados como substitutos razoavelmente úteis;

- avaliações a posteriori - avaliações feitas após uma política de reforma específica ter sido completada e finalizada — são utilizadas com relativa raridade, porque não atendem realmente às necessidades das ações governamentais, são caras e consomem muito tempo. Contudo, podem contribuir para alimentar uma perspectiva de aprendizagem sobre as razões por que tais resultados ou impactos foram gerados, e o valor relativo das ferramentas e processos que foram mobilizados;

- avaliações a priori - ou avaliações feitas enquanto programas de reforma são preparados pelos formuladores de políticas — são mais próximas às quase-avaliações ou avaliações informais: elas podem considerar os resultados comparativos de várias opções que poderiam ser adotadas prospectivamente. $\mathrm{Na}$ verdade permanecem sendo uma fonte relativamente secundária de informações por motivos ligados à pressão de tempo ou às visões políticas que os formuladores de políticas têm em mente;

- avaliações contínuas tendem a acertar mais o alvo como uma ferramenta de gestão, mesmo que elas exijam um monitoramento relativamente intensivo e bem informado. Dessa forma, elas não são adequadas para políticas unilaterais de baixo para cima ou políticas de impacto, particularmente, quando a reforma consiste em transferências ao mercado;

- políticas que visam assegurar a continuidade de ano a ano de reformas de processos internos e de estruturas de departamentos governamentais permitem maior liberdade para o uso de avaliações mais formais e tecnicamente diversas;

- práticas de avaliação podem ser desenvolvidas muito mais facilmente se já houver sistemas de informação sobre custos e desempenhos, apesar de elas não impedirem o desenvolvimento de quase-avaliações.

\section{Gestão de desempenho como um processo de aprendizagem}

Teoricamente, muitos aspectos da atividade do setor público podem ser avaliados: a produtividade e a qualidade dos serviços; a relação entre gastos, bens produzidos e serviços fornecidos; e a extensão pela qual problemas sociais e econômicos são resolvidos, e as metas da reforma são alcançadas. No entanto, na prática, na maioria dos países, a avaliação tende a enfatizar o que pode ser chamado de aspecto interno, ou seja, o 
que se refere à gestão do desempenho da equipe e dos departamentos, sendo o caso da Irlanda, Noruega, Canadá e Nova Zelândia.

Essa abordagem geral, que é mais gerencial do que estratégica, e mais orientada para a eficiência do que para a eficácia, visa fechar o ciclo de informação e manter os formuladores de políticas informados sobre o que está funcionando e o que não está. Ela, muitas vezes, é orientada para a relação entre valor e dinheiro e é desenhada para fornecer informações que serão utilizadas pelos formuladores de políticas para melhorar reformas futuras.

A abordagem gerencial e realista atende às necessidades dos tomadores de decisão e predomina porque geralmente é difícil, e até mesmo arbitrário, avaliar reformas em termos de sua eficácia geral externa. É por isso que as metas e os objetivos da reforma de gestão do setor público raramente são colocados de uma maneira clara e operacionalmente mensurável quando uma política é definida ou lançada.

Nem sempre pode ser presumido que os indicadores e dados sobre desempenho estarão disponíveis. Muitas vezes, não há sistemas estruturados de informação que meçam tempo despendido, resultados dos departamentos, custos e qualidade intrínseca dos serviços. Torna-se difícil dizer objetivamente o que está sendo feito ou foi feito por uma dada organização ao longo de um dado período de tempo, sem citar comparação entre organizações e agências. Em certos momentos, a tentativa de coletar informações vai de encontro aos sistemas existentes, os quais não estão preparados para a gestão de desempenho, mas sim, para verificar a conformidade ou monitorar orçamentos. Conseqüentemente, existe um risco de que a coleta de dados irá exigir tempo e dinheiro adicionais. A boa vontade das agências responsáveis pelo monitoramento é um fator que não pode ser negligenciado nesse sentido. Porém, argumentar que não faz sentido realizar avaliação porque dados administrativos apropriados estão faltando, é entrar numa discussão circular sobre causa e efeito.

A vantagem de ressaltar a quase-avaliação, visando fornecer resultados aproximados de desempenho, em vez de avaliar impactos externos e desempenho geral, é que evita-se, por meio de um processo gradual e em estágios sucessivos, o dilema da coleta de informações na avaliação das políticas, o que promove uma cultura de informação entre os formuladores de políticas e as agências, sem invocar estatísticos, especialistas em computação e contadores externos no serviço público. Dessa forma, a avaliação tem um efeito preparatório. Um ponto de partida possível poderia ser realizar revisões ad hoc, utilizando os dados disponíveis, enquanto se observam o valor relativo dos instrumentos utilizados e a análise feita. Um estágio posterior seria organizar esse processo em uma escala mais ampla. Por exemplo, uma agência central poderia 
coletar sistematicamente dados de desempenho sobre o sistema como um todo e sobre as agências que o constituem, como na Nova Zelândia, ou um departamento de modernização administrativa poderia incluir dados sobre desempenho a respeito de questões-chave da gestão pública a serem abordadas no ano seguinte, no seu relatório anual (como é feito pelo Escrivão do Conselho Privado do Canadá) etc.

Acima de tudo, a avaliação de desempenho não precisa ser vista como um sistema amplo e centralizado, realizado apenas por especialistas. As boas práticas naturalmente vêem a avaliação de desempenho como uma ferramenta viva de gestão. Em outras palavras, a cultura e as pessoas são seus principais componentes, e a produção de informação é meramente um resultado ou meio para atingir um fim. A meta é aumentar a consciência das pessoas para disseminar um novo tipo de enfoque a respeito de desempenho, custo, qualidade e relevância dos serviços fornecidos, e permitir às agências e às equipes que avaliem a si próprias. Nessa perspectiva, a meta de uma abordagem estruturada para o desempenho em todos os níveis do sistema público é alcançada, permitindo a cada nível produzir a informação que necessita para suas tomadas de decisão cotidianas e para conduzir uma auto-revisão, o que terá um impacto sobre a qualidade do seu trabalho cotidiano. A revisão de desempenho avaliativa do aprendizado por meio da ação torna possível dar credibilidade à avaliação baseada em dados concretos.

Uma resposta que funciona particularmente bem - a qual é sugerida pela experiência da Irlanda, do Canadá e da França - consiste em uma abordagem decentralizada e participativa da avaliação. Uma cultura de desempenho somente pode ser dominada se as agências forem encorajadas a coletar e compartilhar informações sobre as melhores práticas, a promover essas práticas e a encorajar outras agências a fazerem o mesmo. O compartilhar de todos os tipos de melhores práticas é um veículo importante para a reforma, pois envolve os participantes e torna possível obter lições sobre se essas práticas funcionam em diferentes situações e estruturas. As lições terão sido aprendidas quando os atores tiverem adquirido capacidade para ver como uma inovação técnica é relevante para um problema que eles enfrentam no seu nível, e puderem fornecer soluções novas e úteis para seu trabalho cotidiano.

Os formuladores de políticas centrais e as unidades cuja principal missão é a reforma da gestão pública desempenham um papel importante nesse sentido. Eles têm uma responsabilidade dupla que consiste, primeiramente, em assegurar a responsabilidade de unidades básicas por meio do relato vertical, bem como entre departamentos por meio da comunicação horizontal. O centro deveria monitorar o desempenho do setor público. Em seguida, precisa ajudar as agências e departamentos a tomar a iniciativa, 
dar a eles uma visibilidade maior ou até mesmo fornecer incentivos e

apoio, por meio de esquemas de treinamento, seminários ou experiências voluntárias. Em termos práticos, isso obviamente significa que o centro precisa ter as habilidades profissionais necessárias à sua disposição. Isso também significa que ele precisa ser cuidadoso no sentido de atingir o equilíbrio correto entre a uniformidade e a diversidade, combinando uma mistura de abordagens que atendam às necessidades de cada contexto nacional. Atendendo às demandas das unidades locais, sua inventividade e diversidade vão de mãos dadas com o desenvolvimento de uma coordenação geral. $\mathrm{O}$ uso de avaliações informais, que são projetadas para fazer parte da rotina, muitas vezes torna possível introduzir ajustes e mudanças sem atrair a atenção de grupos interessados internos ou externos, que podem ser tentados a usar uma avaliação formal como uma oportunidade para resistir à reforma.

Em resumo: a análise das boas práticas sugere que a avaliação pode aumentar a eficiência, o grau em que as metas são alcançadas com relação aos recursos disponíveis. Também torna possível gerar outras formas de valor agregado que estão longe de ser negligenciáveis; dá visibilidade a um julgamento ou medida em termos da adequação (no nível em que as metas atribuídas são alcançadas); apóia a memória administrativa das soluções de ação; fornece variedade de habilidades para os tomadores de decisão em todos os níveis; apóia uma atitude de sabedoria (agir com conhecimento enquanto se duvida do que se sabe) e ajuda a criar competição por status baseada na habilidade administrativa. Ela poderá, até certo ponto, impressionar usuários e observadores externos.

\section{Otimismo razoável para o futuro}

A reforma do setor público está agora se tornando uma tarefa contínua dos governos. É bem provável que terminaram os dias em que era suficiente decretar uma reorganização governamental, uma vez em cada geração, e então retomar as rotinas cotidianas.

Ao mesmo tempo, as pressões por mudança estão se tornando cada vez mais globais e limitantes, o que colocou países, que têm sido relativamente relutantes em adotar reformas, em uma posição difícil. Dois fatores deveriam ser ressaltados em particular:

- o primeiro é a extensão das formas de parceria na governabilidade dos assuntos públicos. O melhor exemplo é a tendência da UE, em se tornar uma entidade pública que exerça responsabilidades que até agora haviam sido reservadas apenas a países, particularmente, ao alocar recursos financeiros com base em programas ou projetos (fundos estruturais etc.). 
O desenvolvimento dessa parceria entre vários países tem envolvido uma extensão significativa do uso dos procedimentos de avaliação;

- o segundo fator se refere às limitações financeiras. Existem muitos motivos para crer que essas limitações, longe de estarem diminuindo, irão na verdade aumentar no setor público ainda por algum tempo. A União Européia novamente é um caso assim. Os Tratados de Maastricht e Amsterdã estabelecem mecanismos reguladores macroorçamentários que terão um impacto considerável. Os sistemas nacionais, incluindo autoridades subnacionais, assim serão forçados não apenas a limitar seus gastos, mas também a conter sua receita drasticamente. Essas tendências irão reforçar uma abordagem centralizada que irá depender do controle por parte das agências de orçamento. Conseqüentemente, gostando ou não, tanto ministérios nacionais como autoridades locais descobrirão ser necessário aumentar seus esforços para racionalizar, começando com sua eficiência interna: custos, produtividade, qualidade.

Esses desenvolvimentos sugerem que, apesar de a continuidade da privatização dos serviços públicos estar sendo operacionalmente possível, os esforços serão concentrados principalmente nas reformas internas do setor público, como eliminar a duplicação ou simplificar unidades institucionais em vários campos etc. Será cada vez mais difícil e caro para um país permanecer de fora dessa tendência generalizada de reforma. Em outras palavras, pelo menos nos países da OCDE, espera-se que a atual disparidade entre uns poucos países pioneiros e outros países mais cautelosos seja reduzida. A competitividade dos sistemas públicos, que até o momento tem sido um aspecto um tanto quanto retórico, possivelmente tornar-se-á um imperativo bastante real e irá ser sentida até mesmo no cotidiano de departamentos governamentais individuais. Ao mesmo tempo, tornar-se-á mais fácil comparar o desempenho de departamentos e de vários níveis do governo, tanto em nível internacional como dentro de cada país. Apesar da reforma de departamentos governamentais ainda ser uma política na qual, em comparação com outras áreas como saúde, pesquisa e desenvolvimento etc., a possibilidade de comparação e, portanto, a referência a boas práticas e ao benchmarking, tem sido relativamente rara (da mesma forma que a avaliação), a situação provavelmente irá mudar de forma rápida. Agora será mais difícil se recusar a realizar algumas reformas do setor público argumentando que elas são baseadas em considerações ideológicas ou políticas. A reforma está se tornando um imperativo funcional por si mesmo.

Conseqüentemente, a situação geral parece estar mudando em direção a uma extensão relativa das práticas de avaliação: a comparabilidade, a necessidade de uma sintonia fina contínua, as parcerias de grande escala e a regulamentação macroorçamentária terão um papel importante. Não há motivo para acreditar, com relação às boas práticas identificadas 
acima, que exista uma mudança substancial no perfil da avaliação em si.

Ela continuará sendo mais orientada para a eficiência interna do que para a eficácia externa, mais internalizada do que externalizada, informal apesar de mais sistemática, e será acompanhada de mudanças culturais e comportamentais ao mesmo tempo em que se torna cada vez mais conectada com a solução de problemas concretos dos formuladores de políticas etc. A avaliação é, e continuará sendo, uma ferramenta valiosa para qualquer um que deseje aproveitar-se dela.

A lição a ser aprendida da experiência da avaliação no final do século XX é de realismo e de modéstia ao mesmo tempo. Alguns talvez acreditem que ela é decepcionante. Pode-se ter pensado que a pressão por responsabilidade democrática iria gerar maior transparência coletivamente compartilhada por cidadãos com relação ao impacto das reformas públicas na sociedade, e que o uso de métodos de maior orientação científica iria tornar possível implementar sistemas amplos e rigorosos mais rapidamente, mas existem aspectos reconfortantes. A orientação das reformas permanece sob o controle realista dos governos e o uso de métodos científicos não tornou os formuladores de políticas menos responsáveis. Nesse sentido, a avaliação não seguiu o caminho da Planning Programming and Budgeting System (PPBS), que foi uma boa idéia, mas mostrou ser não-utilizável por ser estranho às práticas de elaboração de políticas e ignorou de maneira arrogante o julgamento dos funcionários públicos, pelo contrário: a avaliação ensina uma lição otimista através da sua ênfase no princípio do conhecimento utilizável. Nesse sentido, tanto seu foco em descrever as circunstâncias específicas da ação política e sua habilidade de prever causa e efeito ("se eu escolher esta solução, então ela provavelmente terá este impacto") tornam a avaliação uma ferramenta realista para a ação. É fútil, ingênuo ou arrogante imaginar que as reformas de gestão do setor público:

- visam genuinamente mudar a linha de base do comportamento cotidiano dos funcionários do governo e da forma como as organizações realmente operam;

- podem escolher os processos, estruturas e estratégias que efetivamente criam essas mudanças;

- podem tornar essas mudanças duradouras;

- podem limitar os efeitos indesejados que essas mudanças podem ter sobre o fornecimento eficiente e eqüitativo de bens e serviços à sociedade?

O enfoque sobre informação empírica e as conseqüências das ações de reforma, por meio de métodos modernos de avaliação, pode oferecer proteção contra esforços mal direcionados, especialmente em uma época em que reformas mal sucedidas podem muito bem provar serem tão 
insatisfatórias e danosas quanto a recusa em realizar a reforma propriamente dita. A lição otimista para o futuro é que mais e mais países entraram em um processo de aprendizagem cumulativa a respeito das ações de reforma. A busca por eficiência, eficácia, transparência e responsabilidade democrática não irá mais parar. $\mathrm{O}$ aprendizado significa um processo contínuo e orgânico no qual a avaliação pode oferecer ensinamentos decisivos e não ser vista como uma operação conduzida ocasionalmente. De certa forma e como sugerem os exemplos acima, a análise da administração pública melhorou nos últimos tempos, apesar da diminuição das avaliações externas independentes. O século XXI mostrará que a análise fará parte do governo incluindo a área de reforma do setor público. Requer uma certa maturidade, sofisticação e percepção para utilizar bem informações de avaliação, por exemplo, como uma ferramenta para o aprendizado, que pode auxiliar os governos e o público a formarem pontos de vistas bem embasados e a tomarem decisões acertadas. Operacionalizar administrações que aprendem é a tarefa primordial a qual se deve perseguir.

\section{『Notas}

Artigo apresentado no simpósio "Government of the Future: Getting from Here to There”, promovido pela Organização para Cooperação e Desenvolvimento Econômico (OCDE), em Paris, nos dias 14 e 15 de setembro de 1999. Este texto foi originalmente publicado pela OCDE em inglês e francês sob os títulos: Evaluation as usable knowledge for public management reforms e L'evaluation, source de connaissances applicables aux reformes de la gestion publique, respectivamente. PUMA/SGF (99)6. Copyright. Documento disponível no site www.oecd.org/puma/strat/symposium/doclist.htm. A responsabilidade é da ENAP, com autorização da OCDE. 


\section{|| Referências bibliográficas}

Kessler, M.C., Lascoumes, P., Setbon, M., Thoenig, J.C. (1998), L'Evalution des Politiques Publiques. Paris: L'Harmattan.

Lindblom, C., Cohen, D. (1979), Usable Knowledge: Social Science and Social Problem. New Haven: Yale University Press.

Mintzberg, H. (1980), The Nature of Managerial Work. London: Prentice Hall.

Poluitt, C., et al. (1997), Trajectoires and Options: An International Perspective on the implementation of finnish management reforms. Public Management Reforms: Five country studies. Helsinki: Ministério das Finanças.

Sсніск, А. (1996), The spirit of reform: managing the New Zealand State sector in a time of change. Wellington: Comitê de Serviços Estatais.

Trosa, S. (1992), “La modernization est'ell évaluable?" Politicques et management publique. v. 10 , p. 65-84, dez.

Wildavsky, A. (1979), Speaking Truth to Power. The Art and Craft of Policy Analysis Toronto: Little Brown. 


\section{A avaliação como conhecimento utilizável para reformas de gestão pública Jean-Claude Thoenig}

As reformas do setor público utilizam a avaliação? Quais as boas práticas que a experiência trouxe à tona? A avaliação tem futuro?

No presente relatório, a avaliação é definida como um meio de aperfeiçoar a capacidade de aprender como conduzir mudanças bem-sucedidas e definir resultados alcançáveis nos campos da eficiência e eficácia públicas. Ainda que existam muitas formas, a avaliação pode ser caracterizada, em linhas gerais, como uma atividade dedicada à produção e análise de informações relevantes e pertinentes, a respeito da relação entre os atos públicos, seus resultados e impactos.

\section{La evaluación como conocimiento utilizable en reformas de gestión pública Jean-Claude Thoenig}

¿Las reformas del sector público utilizan la evaluación? ¿Cuáles son las buenas prácticas reveladas por la experiencia? ¿La evaluación tiene futuro?

En el presente informe, la evaluación es definida como un medio para el perfeccionamiento de la capacidad de aprender a realizar cambios exitosos y definir resultados posibles en los campos de la eficiencia y la eficacia públicas. A pesar de que existen muchas formas, la evaluación puede ser caracterizada, en líneas generales, como una actividad dedicada a la producción y al análisis de informaciones relevantes y pertinentes sobre la relación entre los actos públicos, sus resultados e impactos.

\section{Evaluation as usable knowledge for public management reforms \\ Jean-Claude Thoenig}

Do public sector reforms use evaluation? What good practices has experience brought to light? Does evaluation have future?

In the present report, evaluation shall be defined as an instument or means for improving the capacity to learn about conducting sucessful changes and defining achievable outcomes in the fields of public efficiency and effectiveness. While many forms exist, evaluation may be characterised in general as an activity which is devoted to the production and analysis of rigorous and relevant information about relationships between on one side public acts and non-acts, and outcomes and impacts on the other side.

Revista do

Serviço

Público

Ano 51

Número 2

Abr-Jun 2000

Jean-Claude

Thoenig é

diretor de

Pesquisa

do Centro

Nacional

de Pesquisa

Científica,

do Grupo de

Análise de

Políticas

Públicas e

professor

no Institution

Européenne

d'Administration

des Affaires

INSEAD

Traduzido por

René Loncan 